\title{
Hybrid Stand-alone Photovoltaic Systems Sizing Optimization Based on Load Profile
}

\author{
Zulkifli Othman ${ }^{1}$, Shahril Irwan Sulaiman ${ }^{2}$, Ismail Musirin $^{3}$, Ahmad Maliki Omar ${ }^{4}$, Sulaiman Shaari $^{5}$ \\ ${ }_{1,2,3,4}$ Faculty of Electrical Engineering, Universiti Teknologi Mara (UiTM) Selangor, Malaysia \\ ${ }^{5}$ Faculty of Applied Sciences, Universiti Teknologi Mara (UiTM) Selangor, Malaysia
}

\begin{tabular}{l} 
Article Info \\
\hline Article history: \\
Received March 13, 2018 \\
Revised May 14, 2018 \\
Accepted May 30, 2018 \\
\hline Keywords: \\
Classical Evolutionary \\
Programming (CEP) \\
Dolphin Echolocation \\
Algorithm (DEA) \\
Evolutionary Programming \\
(EP) \\
Fast Evolutionary Programming \\
(FEP) \\
Performanca Ratio (PR)
\end{tabular}

\begin{abstract}
This paper presents a sizing optimization technique for Hybrid Stand-Alone Photovoltaic (HSAPV). In this research, three optimization techniques have been developed, namely Dolphin Echolocation Algorithm (DEA), Fast Evolutionary Programming (FEP), and Classical Evolutionary Programming (CEP). These techniques have been incorporated into the sizing process to maximize the technical performance of the SAPV system. The components of PV modules, charge controllers, inverters, and batteries are used to determine the optimum value. These components are used as the control parameters to maximize the expected performance ratio (PR) of the SAPV system. The Iterative Sizing Algorithm (ISA) is the benchmarking technique to conduct the optimization technique achieving maximum PR value and minimal computation time. Results obtained from the research show that DE overcomes FEP and CEP. In addition, the optimization techniques also demonstrated comparatively fast with respect to ISA as the benchmark technique.
\end{abstract}

Copyright $@ 2018$ Institute of Advanced Engineering and Science. All rights reserved.

\section{Corresponding Author:}

Zulkifli Othman,

Faculty of Electrical Engineering,

Universiti Teknologi Mara (UiTM) Selangor, Malaysia

Email: 1sntl@ccu.edu.tw

\section{INTRODUCTION}

Solar energy is one of the promising types of renewable energy resources in Malaysia with a potential total installed solar electricity capacity of more than $6500 \mathrm{MW}$ [1]. The solar electicity is generated using either the Grid-Connected Photovoltaic (GCPV) systems or Stand-Alone Photovoltaic (SAPV) systems. Mostly, GCPV systems which are widely installed in urban areas where the supply from utility grid is highly available. An SAPV system typically consists of PV arrays, solar batteries as well as power conditioning units such as charge contollers and inverters. Besides that, the system could also be hybridized with other energy resources such as wind, hydro and diesel generator. Moreover, the type, capacity, size and configurations of these system components are commonly selected through a systematic process known as sizing [1], [2]. For PV-battery-diesel generator normally called as a HSAPV systems.

HSAPV system usually consists of PV modules, such as power conditioning unit charge controller and inverter, a battery bank for storage charges and diesel generator (DG). The size of the HSAPV system appears to be more complex and difficult than the size of the photovoltaic system grid-connected since more components should be considered in the HSAPV system. In [3], [4], the sizing parameters of the HSAPV system is more complicated since the system cannot receive immediate back-up from the utility grid. The size of the HSAPV system usually requires system designers to initially choose PV modules, charge controller, battery bank, inverter and diesel generator before trying to match the electrical characteristics among these components. 
However, if there is more than one HSAPV model, the sizing process is repeated to achieve the most suitable parameters for the design. The conventional sizing process has experienced computational burden as reported in [5], [6]. Several studies have been conducted to accelerate the overall sizing process in HSAPV design. Most approaches made use of various types of Computational Intelligence (CI) techniques. One of the popular optimization techniques that have been widely employed is Artificial Intelligence (AI) [7]. AI technique has dealt with difficult problems in some areas; which in turns alleviated the setback experienced in the existing conventional techniques.

There are three important components in AI namely, the Artificial Neural Network (ANN), Fuzzy Logic (FL) and Evolutionary Computation (EC) [8]. The three main branches of AI have their own different applications.On the other hand, EC is commonly used for population-based metaheuristic optimization process. Generally, there are four main branches for Evolutionary Computation (EC) which are Genetic Algorithm (GA), Genetic Programming (GP), Evolutionary Strategy (ES) and Evolutionary Programming (EP) [9]. In addition, EP and DEA are categorized as the population-based techniques. These meta-heuristic methods are also classified as part of CI.

This paper presents a Hybrid Standalone Photovoltaic System sizing optimization based on load profile. There are three optimization techniques have been developed, used to determine the optimum PV modules, charge controllers, inverters, battery and diesel generator. Comparative studies have been performed FEP, CEP and DEA; while, the ISA used as the benchmark technique.

\section{SYSTEM DESCRIPTION}

This section illustrates the method for sizing HSAPV system. The HSAPV system seen in this research is a PV-battery-ganset power system with AC load as shown in Figure 1.

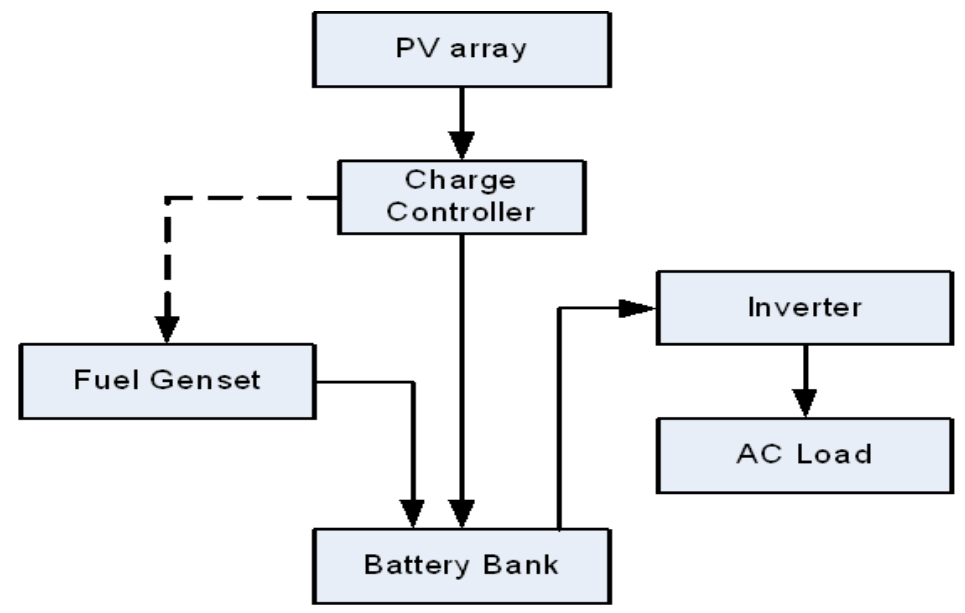

Figure 1. Block diagram of HSAPV system

The main thing before forming a HSAPV system, load demand should be determined first. In this research, data were collected from a rural area in Kalabakan, Sabah, Malaysia. The estimated daily load demand and monthly solar radiations are shown in Table 1 and Table 2 respectively.

Table 1. Daily Load Profile

\begin{tabular}{|c|c|c|c|c|c|c|c|c|}
\hline Appliance & $\begin{array}{l}\text { Number of } \\
\text { units }\end{array}$ & $\begin{array}{l}\text { Power } \\
\text { per unit }\end{array}$ & $\begin{array}{l}\text { Power } \\
\text { factor }\end{array}$ & $\begin{array}{l}\text { Usage } \\
\text { Times }\end{array}$ & Energy & $\begin{array}{l}\text { Usage } \\
\text { Times }\end{array}$ & Energy & $\begin{array}{l}\text { Surge } \\
\text { factor }\end{array}$ \\
\hline & & & & & $\begin{array}{l}\text { Dry season } \\
\text { (jan..jun) }\end{array}$ & & $\begin{array}{l}\text { Wet season } \\
\text { (jul..dec) }\end{array}$ & \\
\hline $240 \mathrm{ac}, 50 \mathrm{~Hz}$ & & W & W & $\mathrm{h}$ & Wh & h & Wh & \\
\hline Water pump & 3 & 120 & 0.7 & 2 & 720 & 1 & 360 & 5 \\
\hline $\begin{array}{l}\text { Incandescent } \\
\text { bulb }\end{array}$ & 15 & 40 & 1 & 10 & 6000 & 13 & 7800 & 1 \\
\hline Television & 3 & 80 & 0.95 & 8 & 1920 & 6 & 1440 & 1 \\
\hline Stand fan & 3 & 60 & 0.6 & 4 & 720 & 10 & 1800 & 3 \\
\hline \multicolumn{5}{|c|}{ Daily Average AC Load Demand (Wh) } & 9360 & & 11400 & \\
\hline
\end{tabular}

BEEI, Vol. 7, No. 2, June 2018 : 153 - 160 
Table 2. Expected Mothly Solar Irradiation [11]

\begin{tabular}{|c|c|c|c|c|c|c|c|c|c|c|c|c|}
\hline month & jan & feb & mar & apr & may & jun & jul & aug & sept & oct & nov & $\mathrm{dec}$ \\
\hline $\begin{array}{l}\text { Irradiation, } \\
\mathrm{G}\left(\mathrm{Wh} / \mathrm{m}^{2}\right)\end{array}$ & 4000 & 4320 & 4400 & 4460 & 4500 & 4700 & 5100 & 5180 & 5100 & 5090 & 5110 & 5050 \\
\hline
\end{tabular}

\subsection{System Determination}

The steps for sizing the SAPV system are defined as follows [10]:

Step 1: Determine the required total energy demand, $E_{\text {required_daily }}$

$$
E_{\text {required_daily }}=\frac{E_{A C}}{\eta_{\text {inv }}}
$$

Where $E_{A C}$ is the total energy required daily for AC load as delivered by the battery in Wh, $\eta_{\text {inv }}$ is the average efficiency of the inverter used for the designed AC loads.

Step 2: Calculate the System Voltage (SV) for the HSAPV system. The SV can be selected as $12 \mathrm{~V}, 24 \mathrm{~V}$ or $48 \mathrm{~V}$ depending on size of load demand required as shown in Table 3.

Table 3. Range of SV [10]

\begin{tabular}{ccc}
\hline & Condition & $\begin{array}{c}\text { Recommended } \\
\mathrm{SV}(\mathrm{V})\end{array}$ \\
\hline Case 1 & $E_{\text {required_daily }} \leq 1 \mathrm{kWh}$ & 12 \\
Case 2 & $1 \mathrm{kWh} \leq E_{\text {required_daily }} \leq 4 \mathrm{kWh}$ & 24 \\
Case 3 & $E_{\text {required_daily }} \geq 4 \mathrm{kWh}$ & 48 \\
\hline
\end{tabular}

Step 3: Determine the total capacity required daily, $C_{\text {required_daily }}$

$$
C_{\text {required_daily }}=\frac{E_{\text {required_daily }}}{S V}
$$

Step 4: Determine the battery bank capacity required, $C_{\text {bank_required }}$

$$
C_{\text {bank_required }}=C_{\text {required_daily }} x \frac{T_{\text {autonomy }}}{D O D_{\max }}
$$

where $D O D_{\max }$ is the maximum battery depth of discharge. $T_{\text {autonomy }}$ represents the expected number of days that the load demand will be happened by battery bank without sunlight availability.

Step 5: Determine the total load current from the battery bank, $I_{\text {total_load_current }}$ and the battery bank discharge rate, $T_{\text {bank_disch }}$

$$
\begin{aligned}
& \mathrm{I}_{\text {total_load_current }}=\frac{1}{\mathrm{SV}}\left[\sum \text { DCPower }+\frac{\sum \text { ACPower }}{\eta_{\mathrm{inv}}}\right] \\
& T_{\text {bank_disch }}=\frac{C_{\text {bank_required }}}{I_{\text {total_load_current }}}
\end{aligned}
$$

where $T_{\text {bank_disch }}$ is the discharge rate of battery bank in $\mathrm{h}$.

Step 6: Determine the battery bank configuration, i.e. the number of battery in series string, $N_{\text {series_bank, }}$, number of battery strings in parallel, $N_{\text {parallel_bank }}$ and bank capacity of the selected battery, $C_{\text {bank_selected, }}$

$$
N_{\text {series_bank }}=\frac{S V}{V_{\text {nom_batt }}}
$$

where $V_{\text {nom_batt }}$ is the nominal battery voltage and $C_{\text {per_battery }}$ is the AH capacity which can selected from the datasheet

$$
\begin{aligned}
N_{\text {parallel_bank }} & =\frac{C_{\text {revised_bank_required }}}{C_{\text {per_battery }}} \\
C_{\text {bank_selected }} & =N_{\text {parallel_bank }} X C_{\text {per_battery }}
\end{aligned}
$$


Step 7: Based on MPPT charge controller; determine the maximum and minimum number of series PV module based on open circuit voltage. $N_{\text {series_max_based_on_Voc }}$ and $N_{\text {series_min_based_on_Voc. }}$.

$$
\begin{aligned}
& N_{\text {Series_max_based_on_Voc }}=\frac{0.95 \times V_{\max \_c c}}{V_{\max \_c}} \\
& N_{\text {series_min_based_on_Voc }}=\frac{1.1 \times V_{\min \_w i n \_c c}}{V_{\min \_m p} x f_{p v \_c c}}
\end{aligned}
$$

where $V_{\text {max_cc }}$ is the maximum input voltage rating of the charge controller and $V_{\text {max } \_c}$ is the maximum open circuit voltage rating of PV module. $V_{\text {min_window_c }}$ is the minimum allowable window input voltage to the MPPT of the charge controller, $V_{\text {min } \_ \text {mp }}$ is the minimum voltage at maximum power of PV module and $f_{p v_{-} c c}$ is cabling efficiency from PV to charge controller.

Step 8: Determine the maximum number of series PV module based on maximum power voltage, $N_{\text {max__series_based_on__Vmp }}$

$$
N_{\text {series_max_based_on_Vmp }}=\frac{0.95 \times V_{\max \_w i n \_c c}}{V_{\max \_m p}}
$$

Where $V_{\text {max_win_cc }}$ is the maximum window voltage of the charge controller and $V_{\text {max } m p}$ is the maximum voltage at maximum power at $\mathrm{PV}$ module.

Step 9: Determine the corrected output power of module, $P_{\text {mod_corrected }}$ and sub-system efficiency, $P_{\text {mod_corrected }}$

$$
P_{\text {mod_corrected }}=P_{m p \_s t c} X f_{\text {temp }} X f_{m m} X f_{\text {dirt }}
$$

Where $P_{m p \_s t}$ is the rated power at STC, $f_{\text {dirt }}$ is the derating factor for dirt, $f_{m m}$ is the derating factor of the manufacturing tolerance and $f_{\text {temp }}$ is the derating factor for temperature.

$$
\eta_{p v_{-} s s}=\eta_{p v_{-} \text {cable }} X \eta_{\text {controller }} X \eta_{\text {batt }}
$$

Where $\eta_{p v_{-} \text {cable }}$ is the efficiency of cable from PV array to battery, $\eta_{\text {controller }}$ is the efficiency of the MPPT charge controller and $\eta_{\text {batt }}$ is the efficiency of the battery.

Step 10: Determine the total number of PV modules for the PV array, $N_{T_{-} m p p t}$

$$
N_{T \_m p p t}=\frac{E_{\text {required_daily }} \times f_{o}}{P_{\text {mod_corrected }} \times P S H \times \eta_{p v_{\_} s s}}
$$

Where $\eta_{p v_{-} s s}$ is the sub-system efficiency of PV array and $P_{m p \_s t c}$ is the rated maximum power at Standard Test Conditions (STC).

Step 11: Determine the number of parallel PV modules, $N_{P_{-} m p p t}$,

$$
N_{P \_m p p t}=\frac{N_{T \_} m p p t}{N_{S_{\_} m p p t}}
$$

where $N_{S_{-} m p p t}$ is the total number of PV modules in series between $N_{\text {series_max }}$ and $N_{\text {series_min }}$

Step 12: Determine the peak capacity of array using the MPPT charge controller, $P_{\text {array_mppt_cc }}$

$$
P_{\text {array_mppt_cc }}=P_{m p \_m o d \_s t c} X N_{s_{-} m p p t} X N_{P \_m p p t}
$$

Step 13: Determine the apparent power of the inverter required for 30 minutes at maximum demand.

$$
S_{i n v_{-} 30 \min }=S_{\text {max_AC_demand }} X S f_{\text {inv }}
$$

Step 14: Determine the apparent power of the inverter required for surge demand.

$$
\begin{aligned}
& S_{\text {inv_surge }}=S_{\text {max_AC_surge }} X S f_{\text {inv }} \\
& S_{\text {max_AC_surge }}=\frac{P_{\text {real }}}{P F} X S_{f}
\end{aligned}
$$


where $S_{i n v 30 \text { min }}$ is the apparent power of the inverter at maximum demand, $S_{\text {invsurge }}$ is the surge rating of the inverter, $S_{\text {max_AC_surge }}$ is AC the surge load demand, $S_{\text {max_AC_demand }}$ is the maximum AC load demand, $S f_{i n v}$ is the safety factor of inverter, $P_{\text {real }}$ is the real power consumption when running, $S_{f}$ is the surge factor and $P F$ is the power factor.

Step 15: Determine the minimum size of diesel generator;

$$
S_{g e n \_m a x \_d e m a n d}=\frac{\left(S_{\max \_A C \_d e m a n d}-S_{i n v \_30 \min }\right)}{f_{\text {derate }}} X f_{g o}
$$

where $S_{\text {gen_max_demand_parallel }}$ is the minimum diesel generator rating based on power demand, $\mathrm{S}_{\text {max_AC_demand }}$ is the maximum AC load, $\mathrm{S}_{\text {inv_30min }}$ is the 30 minutes' apparent power rating of the inverter, $f_{g o}$ is diesel generator factor and $f_{\text {derate }}$ is the total derating factor. $S_{\text {gen_max_surge }}$ can be calculated using Equation (21).

$$
S_{g e n \_m a x \_s u r g e}=\frac{\left(S_{\text {max_AC_surge }}-S_{\text {inv_surge }}\right)}{f_{\text {derate }}} X f_{g o}
$$

where $S_{\text {gen_max_surge }}$ is the minimum diesel generator rating based on surge condition, $\mathrm{S}_{\text {max_AC_surge }}$ is the AC surge load demand and $S_{\text {inv_surge }}$ is the surge rating of the inverter.

$$
S_{g e n \_b a t t}=\frac{\left(S_{\text {batt_charger }}-S_{\text {max_AC_demand }}\right)}{f_{\text {derate }}} X f_{g o}
$$

where $S_{\text {gen_batt }}$ is the diesel generator rating based on battery charging and maximum load profile.

Step 16: Calculate the Performance Ratio, $P R$

$$
P R=\frac{E_{\text {Sys_exp }}}{P_{\text {array_stc }} x P S H_{\text {anual }}}
$$

where $E_{\text {sy_exp }}$ is the expected $\mathrm{kWh}$ output of the system and $P_{\text {array_stc }}$ is the nominal PV array power at STC. PSH represents the estimated annual PSH derived from Table 2.

\section{DOLPHIN ECHOLOCATION ALGORITHM}

Natural resources have inspired many of the man-made technologies. Researchers believe that dolphins are the second to humans in smartness and intelligence. Dolphin can use the echolocation method to help them navigate better in underwater such as to find foods or communicating. The sounds which produced from a dolphin are in the form of clicks which has higher frequency than the sound for communication. These clicks create sound waves that able to travel quickly and when the sound waves bounce off objects around them, they return to the dolphins as echoes and the dolphins can determine the distance [12].

Basically, the DEA-based optimization process, it starts with the initialization of an objective function. After that, the Predefined Probability of a loop, PP $\left(\operatorname{Loop}_{i}\right)$ and the Accumulative Fitness of the $i_{t h}$ alternative to be chosen for the $j_{t h}$ variable, $\mathrm{AF}_{\mathrm{ij}}$ are calculated using

$$
\begin{aligned}
& P P\left(\operatorname{Loop}_{i}\right)=P P\left(\operatorname{Loop}_{1}\right)+\left(1-P P\left(\text { Loop }_{1}\right)\right) \times\left(\frac{\text { Loop }_{i}-1}{\text { LoopNumber }-1^{\prime}}\right) \\
& A F_{i j}=\frac{1}{R_{e}} \times\left(R_{e}-|k|\right) \times \text { Fitness }(i)+A F_{i j-1}
\end{aligned}
$$

where $P P\left(L_{o o p}\right)$ is the convergence factor of the first loop. Loop $i$ is the number of current loop and LoopNumber is the number of loops. $A F_{i j-1}$ is the previous AF of the $i_{t h}$ alternative to be chosen for the $j_{t h}$ variable. Besides, $R_{e}$ is the valuable radius where the AF of the $i_{t h}$ alternative to be chosen for the $j_{t h}$ variable is affected from its fitness. This radius is recommended to be not more than quarter of the search space [13]. $k$ is the positive and negative value for the effective radius where the AF of the $i_{t h}$ alternative to be chosen for the $j_{t h}$ variable are affected from its fitness and Fitness $(i)$ is the fitness of the location $i$.

Next, a small value of $\varepsilon$ is added to AF are consistently in the search space for the selected option. Up to now, previous studies have indicated that, the value of $\varepsilon$ is important and superior to be less than the minimum value achieved for the fitness [13].

$$
A F=A F+\varepsilon
$$

After that, set the $A F=0$ for the best candidates from the population while the rest of the candidates are maintained with the original value for their $A F$. The step can be defined as follows:

For $j=1$ : Number of variables ; $i=1$ : Number of alternatives; If $i=$ The best location $(j)$ 


$$
A F_{i j}=0
$$

Next step is to determine the probability, $P_{i j}$ of choosing the $i_{t h}$ alternative for all the number of variables, $j$ is calculated using:

$$
P_{i j}=\frac{A F_{i j}}{\sum_{i=1}^{L A j} A F_{i j}}
$$

After that, $P P\left(\operatorname{Loop}_{i}\right)$ is allocated to all alternatives chosen for all variables. Then, the next location of candidate is determined according to the probabilities assigned to each alternative. In this study, the PR value was determined based on the fitness value of each candidate. The results were ranked accordingly to their fitness values with the candidate having maximum PR. Finally, all steps are repeated until the maximum loop numbers is reached.

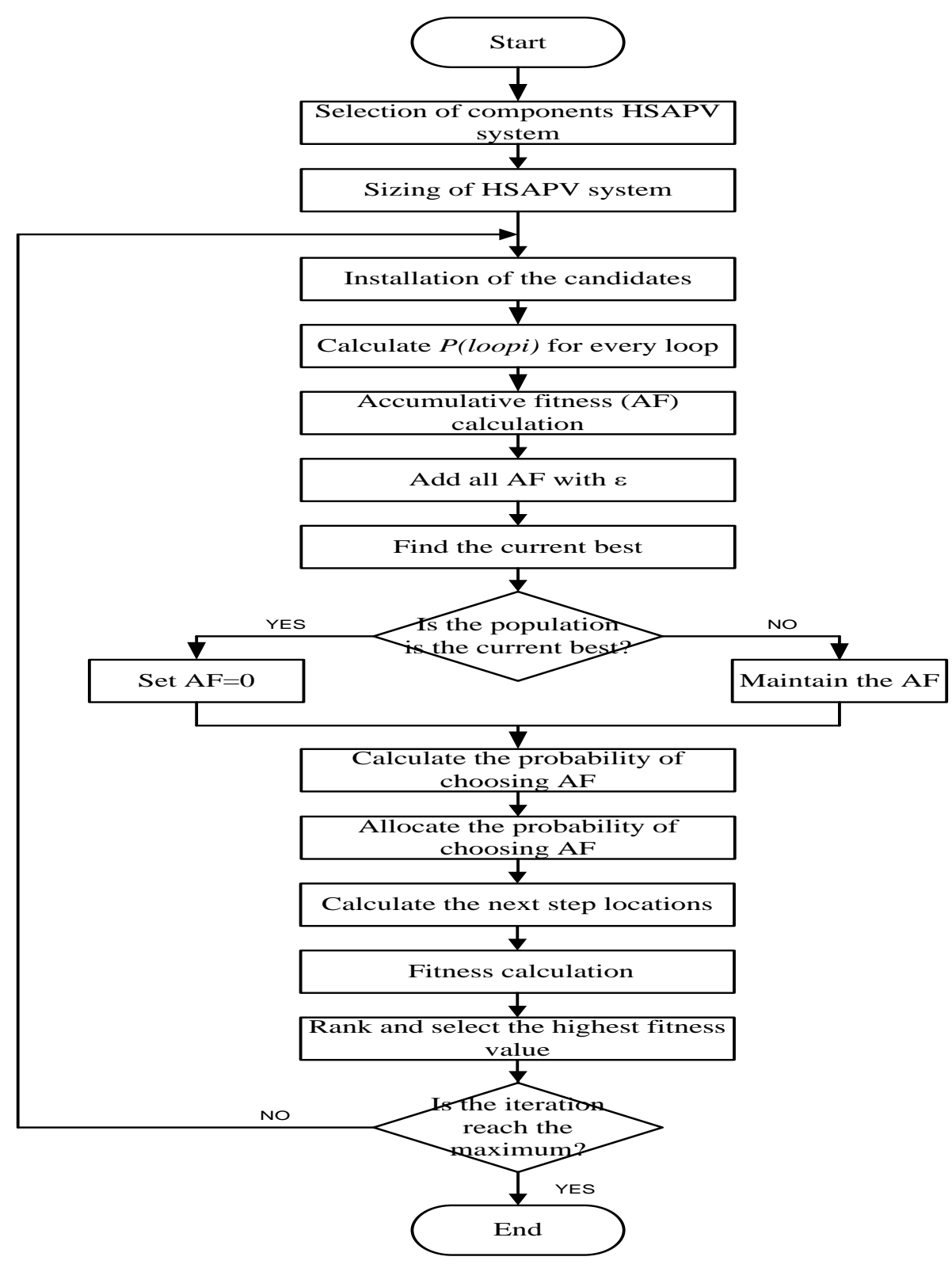

Figure 2. Flowchart of Sizing and optimization technique using DEA 


\section{RESULTS AND ANALYSIS}

This section describes the results of HSAPV system using DEA and EP models with ISA as shown in Table 4. These results finding the maximized PR and the optimal configuration among set of system components which can meet the load demand requirements. From the table, it is observed that all the four technique ISA, DEA, CEP and FEP conclude no of inverter code is 7. Beside that, the number of charge controller code identified by ISA, DEA and FEP is identical, i.e. 7; while, CEP determines 8 as the charge controller code value. ISA is the technique for the benchmarking of the whole optimization algorithm techniques. Apart from that, the performance DEA and FEP was found to produce the optimal value of PR with ISA, i.e. 0.7682. However, DEA has speed up the computation time to accomplish the minimal value. This result shows $91.32 \%$ faster than ISA technique.

Table 4. Performance of Comparison of DEA and EP Models with ISA

\begin{tabular}{ccccc}
\hline \multirow{2}{*}{ Results } & \multirow{2}{*}{ ISA } & \multicolumn{2}{c}{ EP Techniques } & \multirow{2}{*}{ DEA } \\
\cline { 3 - 4 } & & CEP & FEP & \\
\hline Battery code & 12 & 12 & 12 & 12 \\
PV code & 12 & 6 & 12 & 12 \\
Inverter code & 7 & 7 & 7 & 7 \\
Charge Controller code & 7 & 8 & 7 & 7 \\
Diesel Generator Code & 11 & 11 & 11 & 11 \\
N_batt_s & 8 & 8 & 8 & 8 \\
N_batt_p & 2 & 2 & 2 & 2 \\
N_pv_s & 2 & 3 & 2 & 2 \\
N_pv_p & 8 & 6 & 8 & 8 \\
Nt_inv & 1 & 1 & 1 & 1 \\
Nt_cc & 2 & 2 & 2 & 2 \\
Nt_diesel_gen & 1 & 1 & 1 & 1 \\
Optimal, PR & 0.7682 & 0.7428 & 0.7682 & 0.7682 \\
Comp. time, (s) & 2003.04 & 174.58 & 174.02 & 173.91 \\
\hline
\end{tabular}

The next analysis is the maximization of PR based on four techniques by using different population size is tabulated in Figure 3. Based on figure, for the small size population $(n=5)$, the range of maximum PR for three optimization is 0.71-0.750 compare with ISA (i.e 0.7628). Furthermore, when the population size is increased, the values of fitness values are increase accordingly. On the other hand, the FEP and DEA reached the maximum value of PR (i.e 0.7628) with population size of 30 as those set by ISA, while the CEP is reached at value 0.7448 until the end of population size. In addition, the DEA is maintained with the maximum value of PR at population size of 25 onwards (i.e 0.7628), while the FEP is reached the maximum PR at population size of 30. These mean that DEA is better than CEP and FEP in optimizing the HSAPV system for maximization of fitness value.

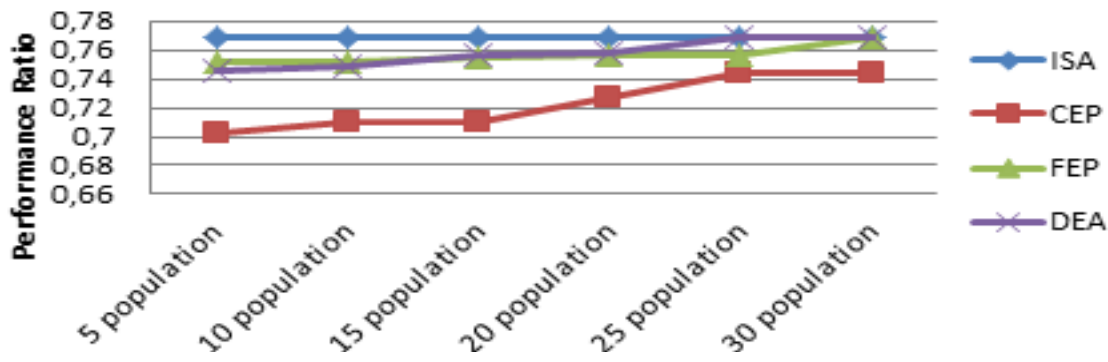

Figure 3. Performance of fitness value with different techniques at different number of population

\section{CONCLUSION}

This paper has presented Hybrid Standalone Photovoltaic Systems Sizing Optimization based on load profile.There are three different optimization techniques were investigated before selecting the best optimal value based on sizing algorithm. From the results, the DEA has reached the maximum of fitness values, together with the minimal computation time. The DEA has been compared with the ISA, whereas ISA is the iterative technique where can produced the optimal value of PR. The development of DEA is also 
feasible for solving the other optimization problems. For future works, DEA could be potentially conducted to apply in multisource of SAPV systems.

\section{ACKNOWLEDGEMENT}

This work was supported in part by the Fundamental Research Grant Scheme (FRGS), Ministry of Education (Ref: 600-RMI/FRGS 4/3 (120/2016)) and Universiti Teknologi MARA (UiTM) Malaysia.

\section{REFERENCES}

[1] Salsabila Ahmad, Mohd Zainal Abidin Ab. Kadir and Suhaidi Shafie, "Current perspective of the renewable energy development in Malaysia," Renewable and Sustainable Energy Reviews 15 (2011) 897-904.

[2] S. I. Sulaiman, T. K. A. Rahman, I. Musirin, S. Shaari, and K. Sopian, "An intelligent method for sizing optimization in grid-connected photovoltaic system," Sol. Energy, vol. 86, no. 7, pp. 2067-2082, 2012.

[3] S. H. El-Hefnawi, "Photovoltaic diesel-generator hybrid power system sizing," Renewable Energy, vol. 13, no. 1, pp. 33-40, January 1998.

[4] Z. Othman, S. I. Sulaiman, I. Musirin, A. M. Omar, S. Shaari, and M. Z. Rosselan, "Sizing Optimization of Hybrid Stand Alone Photovoltaic System,” Int. J. Adv. Sci. Eng. Inf. Technol., 2017; vol. 7 No.6.

[5] A. Chel and G. N. Tiwari, "A case study of a typical 2.32kWP stand-alone photovoltaic (SAPV) in composite climate of New Delhi (India)," Applied Energy, vol. 88, no. 4, pp. 1415-1426, April 2011.

[6] A. Aziz, N. Izzati, S. I. Sulaiman, I. Musirin, and S. Shaari, "New Technique For Optimization Technique Of A Stand-Alone Photovoltaic System," in Journal of Theoretical and Applied Information Technology, vol. 67 No.2, pp. 533-538.

[7] A. Kaabeche, M. Belhamel, and R. Ibtiouen, "Sizing optimization of grid-independent hybrid photovoltaic/wind power generation system," Energy, vol. 36, no. 2, pp. 1214-1222, February 2011.

[8] S. Sulaiman, T. Rahman, and I. Musirin, "Artificial immune system for sizing grid connected photovoltaic system," in $5^{\text {th }}$ International Power Engineering and Optimization Conference (PEOCO), Malaysia, 2011, pp. 398-403.

[9] M. Zakyizzuddin Rosselan, S. Irwan Sulaiman, and N. Othman, "Evaluation of Fast Evolutionary Programming, Firefly Algorithm and Mutate-Cuckoo Search Algorithm In Single-Objective Optimization," International Journal of Electrical \& Electronic Systems Research, vol. 9 No.1; pp. 1-6.

[10] A. M. O. Sulaiman Shaari, Ahmad Hadri Haris, Shahril Irwan Sulaiman, Solar Photovoltaic Power: Designing Stand-Alone System, 1 ed. Malaysia: Ministry of Energy, Green Technology and Water, 2010.

[11] S. I. Sulaiman, S. Shaari, and A. M. Omar, Solar Irradiation Data for Malaysia, 1 st. Sustainable Energy Development Authority Malaysia (SEDA), 2012.

[12] S. Yang, J. Jiang, and G. Yan, “A dolphin partner optimization,” Proc. 2009 WRI Glob. Congr. Intell. Syst. GCIS 2009, vol. 1, pp. 124-128, 2009.

[13] A.Kaveh and N. Farhoudi, "Dolphin Echolocation Optimization : Continuous search space," Advances in Computational Design, vol. 2, no. 2, pp. 175-194, 2016. 